\title{
Integrating CAD and schedule for identification and resolution of work space conflicts between subcontractors
}

\author{
Sy-Jye Guo
}

\begin{abstract}
Numerous workers, equipment, material, temporary facilities, and permanent structures share the limited space during construction. Since space constraints may affect productivity and the critical path, it is essential to organize the available space efficiently and minimize space conflicts. This study considers space availability due to time and scheduling, productivity loss due to space constraints and path interference, as well as the possibility of alternative space to resolve these conflicts and optimize space usage. Herein CAD is integrated with scheduling software for dynamic identification of space conflicts on the job site. Follow-up supplemental decision criteria are then provided for conflict analysis and resolution. A prototype decision support system, which combines the criteria, was developed to solve this significant and complex problem more efficiently and precisely. A case study demonstrates the use and development of this system, which is very helpful to engineers and project management.
\end{abstract}

Key words: space, conflict, resolution, CAD, schedule.

Résumé : Plusieurs travailleurs, pièces d'équipements, matériaux, installations temporaires ainsi que des structures permanentes partagent un espace limité durant la construction. Puisque des contraintes d'espace peuvent affecter la productivité et le chemin critique, il est essentiel d'organiser l'espace disponible efficacement et de minimiser les conflits d'espace. Cette étude considère la disponibilité de l'espace causée par le temps et la planification, la perte de productivité causée par les contraintes d'espace et l'interférence des chemins, ainsi que la possibilité d'espaces alternatifs afin de résoudre ces conflits et d'optimiser l'usage de l'espace. En cela, la CAO est intégrée à un programme de planification afin de permettre une identification dynamique des conflits d'espace sur le site de travail. Des critères de décision supplémentaires de suivi sont ensuite fournis pour l'analyse et la résolution de conflits. Un prototype de système de décision combinant les critères a été développé afin de résoudre ce problème important et complexe de façon plus efficace et précise. Une étude de cas démontre l'utilisation et le développement du système, qui est très utile pour les ingénieurs et les directeurs de projets.

Mots clés : espace, conflit, résolution, CAO, horaire.

[Traduit par la Rédaction]

\section{Introduction}

Building construction involves various subcontractors working in a constrained area. Each subcontractor requires specific work space, equipment space, material storage, and travel paths as well as protected areas to complete his task. A crowded job site is a major cause of productivity decrease and schedule interference or delay. A detailed site layout planning and space allocation for subcontractors reveals the space conflicts in advance and thus improves the overall work flow and efficiency. On the other hand, without a space management plan, the job site can become chaotic, filled with interfered workers, interrupted or inefficient works,

Received January 15, 2001. Revised manuscript accepted April 24, 2001. Published on the NRC Research Press Web site at http://cjce.nrc.ca on August 16, 2001.

S.-J. Guo. Department of Civil Engineering, National Taiwan University, Taipei, Taiwan 106 (e-mail: sjguo@ce.ntu.edu.tw).

Written discussion of this article is welcomed and will be received by the Editor until February 28, 2002. schedule delays, and numerous complaints that can destroy morale.

Traditionally, a site engineer arranges the daily activities on the job site according to the planned schedule. However, this requires space allocation to various trades of workers during specific time frames. Space conflicts occur frequently on many job sites because of the lack of a formal procedure or methodology to identify all potential space conflicts. Even an experienced project manager may not be able to identify all the conflicts, and thus, traditionally, problems are dealt with as they arise. When serious space conflicts occur, the schedule is often delayed. Therefore, if a decision support system can be developed to assist the manager to identify space conflicts and suggest resolutions beforehand, then productivity will be essentially improved on the job site for all the subcontractors.

\section{Literature review}

Space management involves three primary aspects of research: site layout planning, path planning and space scheduling. First, site layout planning deals mainly with the layout 
Table 1. Comparisons and features of space scheduling studies.

\begin{tabular}{|c|c|c|c|c|c|c|}
\hline \multirow[b]{2}{*}{ Researcher } & \multicolumn{2}{|c|}{ Time factor considered } & \multirow[b]{2}{*}{ Space user } & \multirow{2}{*}{$\begin{array}{l}\text { Space } \\
\text { overlap } \\
\text { allowed }\end{array}$} & \multirow{2}{*}{$\begin{array}{l}\text { Space } \\
\text { conflict } \\
\text { analysis }\end{array}$} & \multirow{2}{*}{$\begin{array}{l}\text { Conflict } \\
\text { resolution } \\
\text { strategy }\end{array}$} \\
\hline & $\begin{array}{l}\text { Available } \\
\text { space }\end{array}$ & $\begin{array}{l}\text { Working } \\
\text { space }\end{array}$ & & & & \\
\hline Tommelein & No & Yes & Temporary facility & No & No & No \\
\hline Thabet & Yes & Yes & $\begin{array}{l}\text { Worker, equipment, } \\
\text { material }\end{array}$ & Yes & No & $\begin{array}{c}\text { Schedule } \\
\text { delay }\end{array}$ \\
\hline Riley & Yes & Yes & $\begin{array}{l}\text { Worker, equipment, } \\
\text { material, temporary } \\
\text { facility }\end{array}$ & No & No & Yes \\
\hline Akinci & Yes & Yes & $\begin{array}{l}\text { Worker, equipment, } \\
\text { material, temporary } \\
\text { facility }\end{array}$ & No & Yes & No \\
\hline This study & Yes & Yes & $\begin{array}{l}\text { Worker, equipment, } \\
\text { material, temporary } \\
\text { facility }\end{array}$ & Yes & Yes & Yes \\
\hline
\end{tabular}

of temporary facilities on the job site. Various approaches for locating the most appropriate layout of temporary facilities have been presented (Tommelein and Zouein 1993; Yeh 1995; Cheng and O'Connor 1996; Li and Love 1998; Hegazy and Elbeltagi 1999; Zouein and Tommelein 1999). Geographic information system (GIS), artificial intelligence (AI), and genetic algorithm (GA) have been used in previous studies to decide the best layout, according to the shortest travel distance or minimum travel cost between the temporary facilities. However, it is argued that a minimum travelling distance or cost applies only to a transportation optimization, and not directly to the optimization of the work itself, nor the shortest working period. Previous site layout studies did not pay enough attention to this argument. Furthermore, most of these studies did not consider the impact of time on space availability. For example, the job site office can be moved into the building itself when the structure is partially completed and thus release space for alternative use. As well, time frame impact was neglected or oversimplified in most of these previous studies.

Secondly, path planning studies focus on the shortest route for construction equipment and operations. Based on work requirements and the starting and the destination points, the shortest, collision-free path is identified by various algorithms (Varghese and O'Connor 1995; Tserng et al. 1996; Lin and Haas 1996). Typical applications include routing large vehicles or heavy-lift operations on construction site as well as autonomous landfill using global positioning system (GPS). However, since path planning studies are concerned mainly with equipment, generally workers and material storage are not included. Also, path planning researches assume that space availability is fixed within a specific time period, that is, there is no consideration of the actual space variations during construction. These limitations constrain the significance of path planning studies on the improvement of construction productivity and space conflict resolutions.

Finally, space scheduling combines all working elements (worker, equipment, material, path, temporary facilities, and physical layouts) subjected to the variations of time frames or schedules, and thus eliminates or minimizes space conflicts between these working elements. This complex problem involves space consideration as a resource, which varies with time. The space allocation procedure needs to be formally and accordingly executed based on a set of requirements or constraints of various working elements. Tommelein and Zouein (1993) developed MovePlan to determine temporary facilities according to the CPM schedule. Thabet and Beliveau (1994) defined workspace demand and availability for high rise building construction. He also proposed the concept of space capacity factor (SCF) to describe productivity loss due to space constraints. Then, in 1997, a space-constrained resource-constrained scheduling system (SCaRC) was developed. Riley and Sanvido (1995) defined construction-space use patterns in multistory buildings and presented a space planning method regarding various use patterns (Riley and Sanvido 1997). Recently, fourdimensional space planning specification and construction work space development has been investigated (Riley 1998). Akinci et al. (1998) also executed similar research, which reduces non-value-adding activities due to time-space conflicts. Then, time-space conflict analysis based on a 4D production model was proposed (Akinci and Fischer 1998).

Although many researchers have targeted this complex space-scheduling problem, few studies have used a formal procedure to analyze the patterns of space conflicts and thus provide resolution strategies. Moreover, overlapping work space is not considered by most studies. Table 1 summarizes the major characteristics of previous studies as well as the improvement of this study. This study has attempted to overcome those assumptions and derive a more thorough result than previously studies have achieved.

\section{System structure and analysis flowchart}

This study applied two typical tools, AutoCAD for space planning and MS-Project for scheduling, to target the space conflict problem. Notably, both software packages are well known to most engineers. Once the space conflict is detected, the analytic flowchart provides an appropriate resolution strategy to eliminate or minimize the conflict based on the decision criteria developed herein. Figure 1 shows the system structure. If the conflict is resolved by space reallocation, the resolution will be fed back to the CAD system. The CAD system will display the rearranged space planning 
Fig. 1. System structure of space conflict resolution.

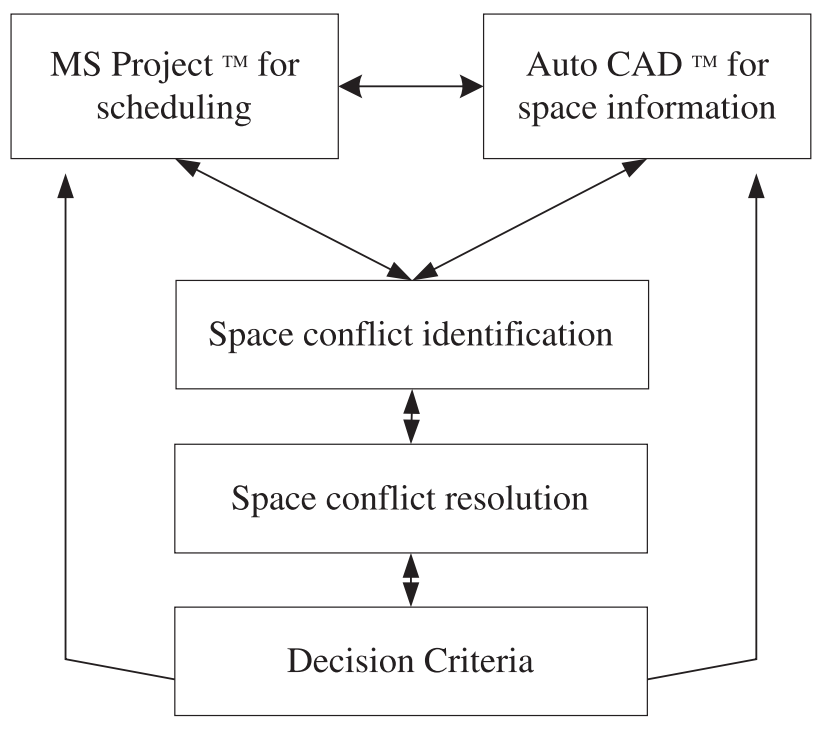

result for various subcontractors. However, if the conflict cannot be eliminated, the system will then suggest a revised schedule, according to the minimized delay caused by space conflicts. Once the original schedule is adjusted to resolve the conflicts, the system will link to MS-Project to update the revised schedule for various subcontractors.

Figure 2 illustrates the analysis flowchart. On completion of the project design, the associated construction method, original schedule/duration, required resources as well as the CAD drawing are then determined. According to the above information, space availability and demand can be compiled based on various activities and time periods. Hence, a preliminary space plan can be derived for space conflicts analysis. Initially, this system will check if there is any space conflicts between the subcontractors according to preliminary space planning. If any space conflict is identified, the systems decision criteria attempt to provide a resolution strategy to either resolve or minimize the conflict. When all the conflicts are resolved, the system will execute the path demand analysis to verify if there is sufficient path space for worker/equipment travelling and material transportation. However, if the path demands cannot be satisfied, then the space conflict resolutions will be redone. Only when path demands are satisfied, are the space conflicts really resolved and the final space planning complete.

\section{Available space and space demand}

The available space within building construction is divided into four categories: exterior of job site, interior of job site, inside the structure, and space provided by temporary structures such as platforms and scaffolds. The first two indicate only ground space. Available space inside the structure is then divided into various stories and zones. The total available space data are then compiled by the different codes of availability categories, which include the space size and time availability.

The space demand, which is derived from the original schedule and broken down as a hierarchical structure, is shown in Fig. 3. Notably, an activity may include several
Fig. 2. Analysis flowchart of space planning and conflict resolution.

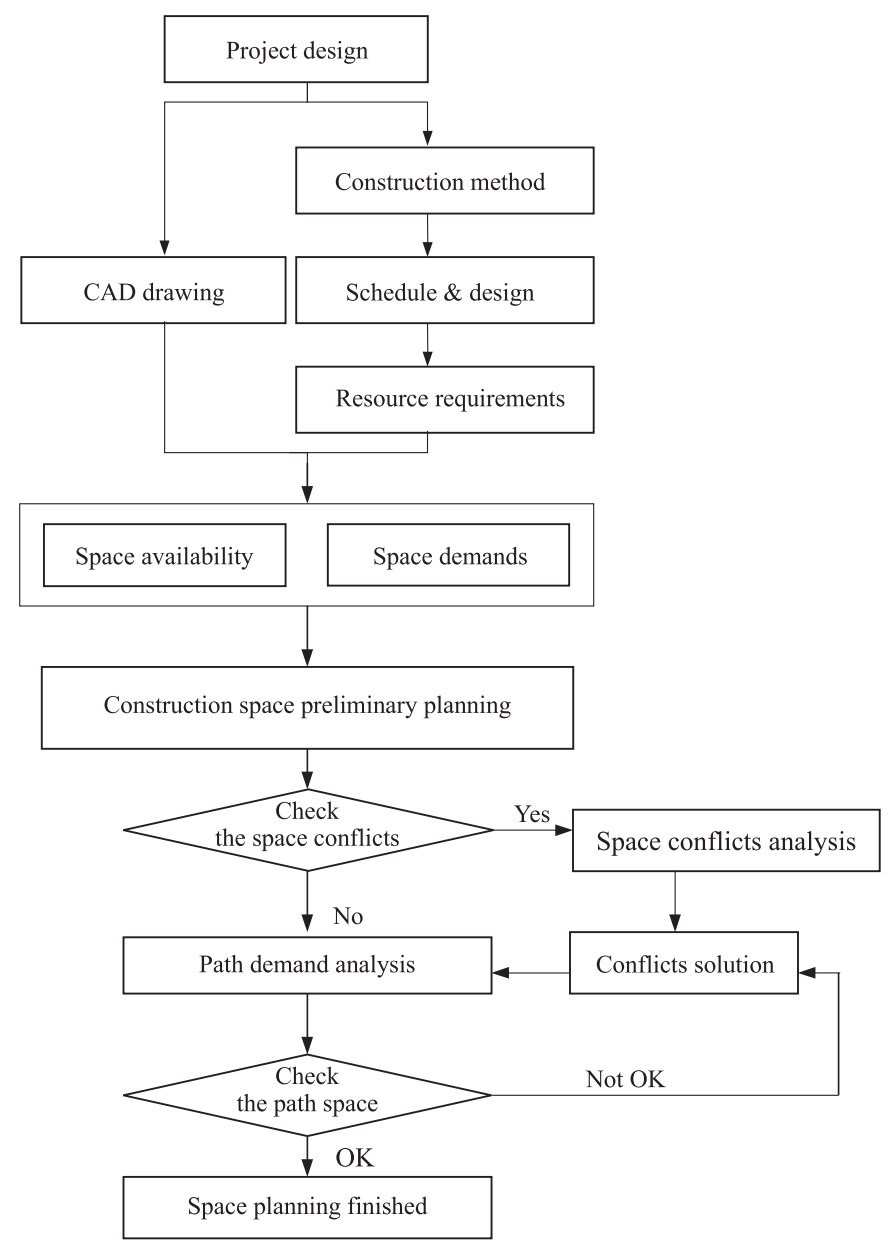

tasks and require various working and path spaces for laborers and equipment as well as associated material storage.

For various activities, different colors are applied for identification within CAD. Table 2 displays the different line patterns for the various spaces, such as working, storage, waste, or set-up space. Notably, the crossed line represents working space, while the equipment working space uses a darker line than the labor working space does. Furthermore, a double crossed line designates material storage space and a straight line identifies the set-up space of temporary facilities. Thus, according to the different colors and patterns on the CAD drawing, the space user can be identified easily.

\section{Space conflict identification}

The space demands for various activities are specified by site engineers and displayed on the CAD drawing. Combining space demands within the same time period reveals conflicts between various activities. This is similar to the combination of various design drawings, which identify physical space conflicts within the final design. During construction, the combination of space demands can assist the engineer to identify potential space conflicts. Figure 4 shows the concept of space conflict identification.

In this study, space conflict is defined as more than one space demand claim on a specific available space during the same time period. Thus, when all the space demands of vari- 
Fig. 3. Hierarchical structure of space demand.

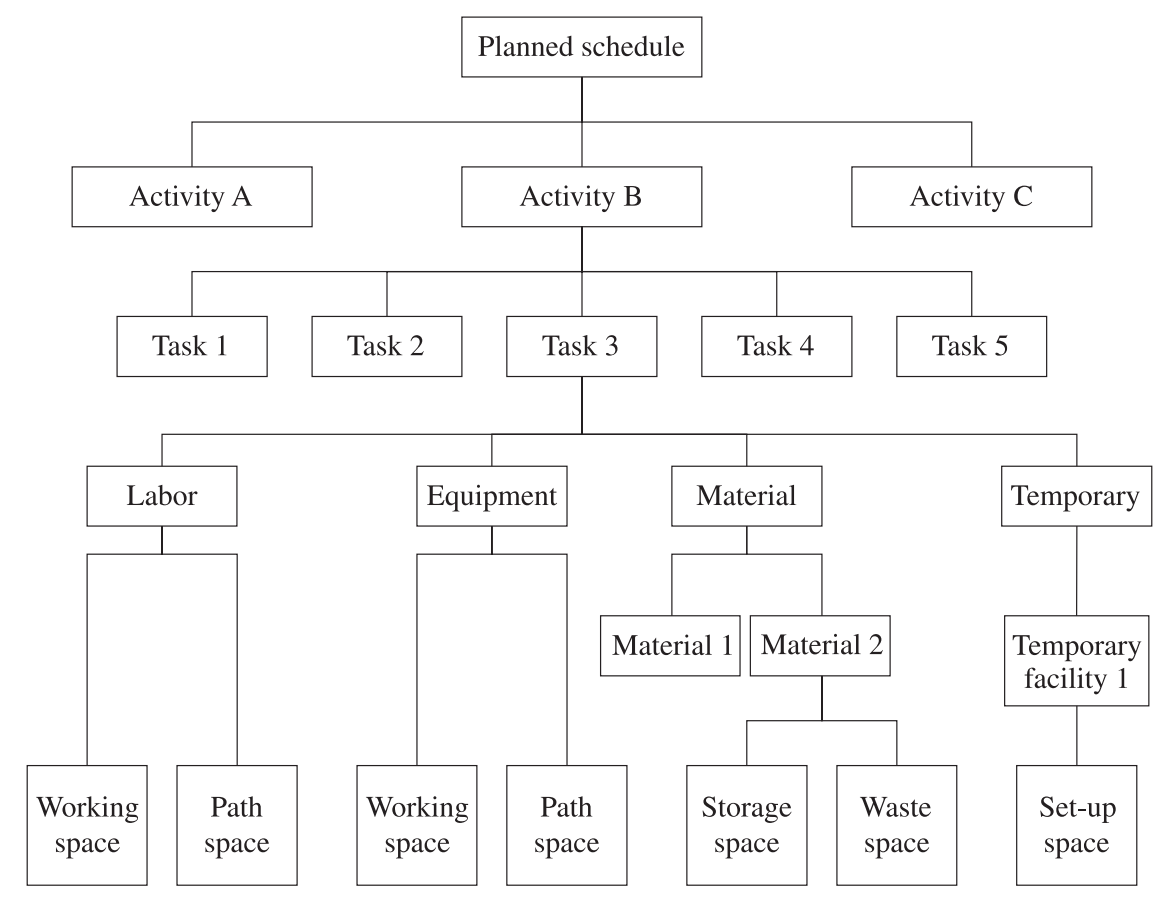

Table 2. Identification of various space demands.

\begin{tabular}{lll}
\hline Space user & Type of space & Identification \\
\hline Labor & Working space & \\
Equipment & Working space & \\
Material & Storage space & \\
Temporary facility & Set-up space & \\
\hline
\end{tabular}

ous subcontractors are overlapped on the CAD drawing for a specific time period, space conflicts can be detected. Table 3 shows a compiled example of space demands for various subcontractors during different time periods.

Once a space conflict is detected, data regarding the affected activities as well as the size of the overlapped space are required for conflict analysis and resolution. The following variables are defined for subsequent analyses:

1. Interference space size: size of overlap between activities

2. Interference space percentage (ISP):

$$
\text { ISP }=\frac{\text { Interference space size }}{\text { Original size }} \times 100 \%
$$

3. Interference duration: length of time for overlapped space demand

4. Interference duration percentage (IDP):

$$
\mathrm{IDP}=\frac{\text { Interference duration }}{\text { Original duration }} \times 100 \%
$$

Figure 5 demonstrates an example of these variables.

\section{Resolution strategy}

To overcome space conflicts, three resolution strategies are considered. The first strategy is to adjust space demand, which changes the location of space demand or divide the original space demand into several smaller areas to eliminate space conflicts. This approach does not alter the original schedule and if it is feasible, it minimizes the impact on the construction site. The second strategy adjusts the planned schedule to avoid space conflicts. Typical solutions for this strategy include adjusting the starting time of an activity, reducing the length of time for space requirement, or splitting the working time period. Typically, this approach delays the original schedule; however, a minimum delay is the decision criteria for space conflict resolution. The third strategy is a hybrid approach, which adjusts space demand and scheduling sequence simultaneously. Thus, changing the quantity of space users or even the construction method may reslove space conflicts.

\section{Criteria for resolving space conflict}

Once the strategy is established, criteria that determine the activity to be modified become essential. To resolve space conflicts, the characteristics for each involved activity must be analyzed. Hence, this research develops a series of criteria for analyzing conflicts characteristics and assists the engineer in deciding which activity requires adjustment:

1. Logic sequence between activities: If conflict is identified, the logical sequence between these activities is verified initially. If a logical sequence relationship exists, the space demand for successive activities must be adjusted.

2. Critical path: Activities on the critical path have the priority to claim space demand; other noncritical activities will be modified. 
Fig. 4. Concept for identifying space conflicts.

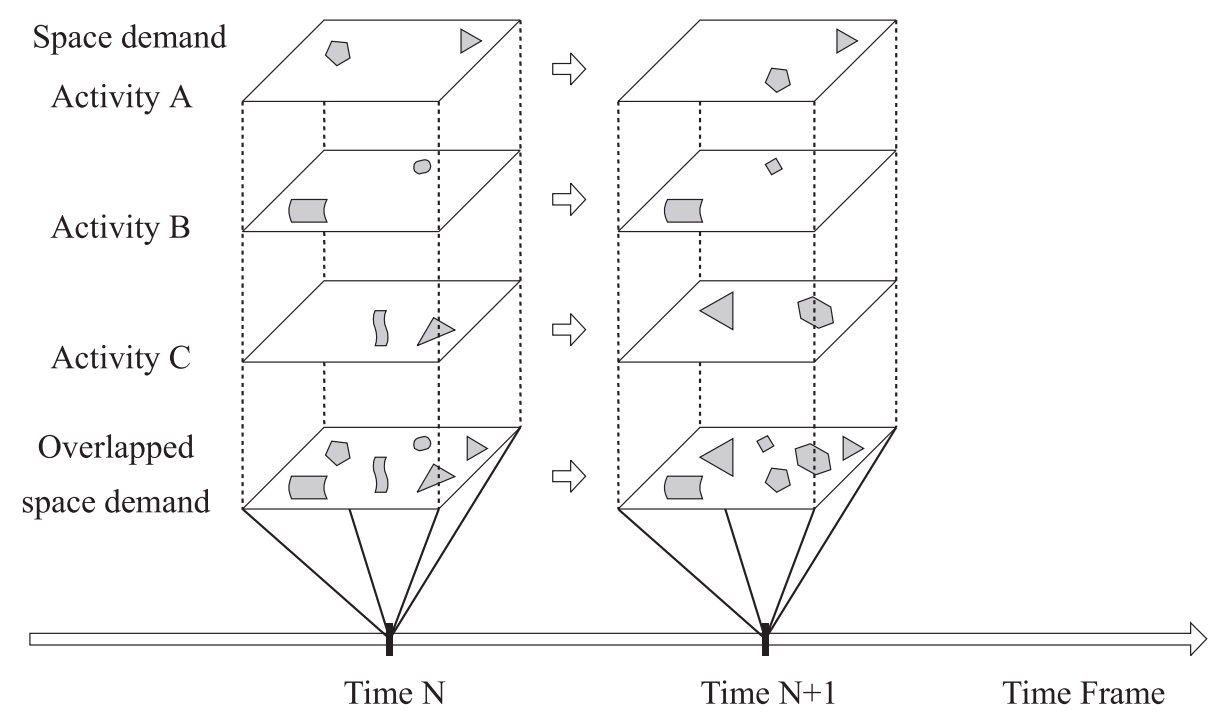

Fig. 5. Data example for overlapped space demand.

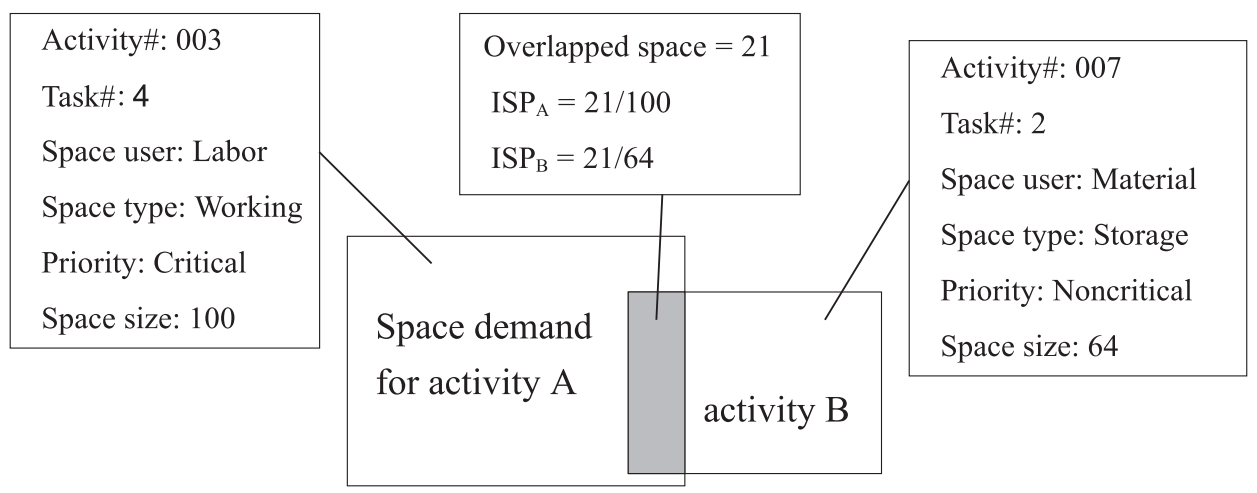

Table 3. Example of space conflict identification.

\begin{tabular}{|c|c|c|c|c|c|c|}
\hline \multirow{2}{*}{$\begin{array}{l}\text { Conflict } \\
\text { No. }\end{array}$} & \multirow[b]{2}{*}{ Activity } & \multirow{2}{*}{$\begin{array}{l}\text { Task } \\
\text { code }\end{array}$} & \multirow[b]{2}{*}{ Space user } & \multirow[b]{2}{*}{ Type of space } & \multicolumn{2}{|c|}{ Time overlap of conflicts } \\
\hline & & & & & 1st day a.m. & 1st day p.m. \\
\hline \multirow[t]{2}{*}{$7-1$} & Reinforced steel & $7-3$ & $\begin{array}{l}\text { Reinforced steel } \\
\text { labor }\end{array}$ & Working space & $\mathrm{X}$ & \\
\hline & Plumbing & $7-4$ & Plumbing labor & Working space & $\mathrm{X}$ & \\
\hline \multirow[t]{2}{*}{$7-2$} & Reinforced steel & $7-3$ & Column & Storage space & & $\mathrm{X}$ \\
\hline & Plumbing & $7-4$ & Conduit & Storage space & & $\mathrm{X}$ \\
\hline
\end{tabular}

3. Space divisibility: If the space demand can be divided into several smaller areas, then the space conflict may be eliminated.

4. Location change: If the space demand, such as material storage, can be altered, then the space conflict may be eliminated.

5. Space size modification: If the space demand can be adjusted or decreased, i.e., constrained to a specific limit, the space conflict could be eliminated. However, the productivity of the adjusted activity may be affected.

6. Start time of conflicting space occupation: The start time of an activity to occupy a space could be a criterion for deciding which activity requires adjustment.

7. Length of occupancy time: The duration of occupancy could also be a criterion for deciding the conflict resolution approach.
Despite the aforementioned criteria, additional factors may also help to analyze and resolve the conflicts. These affiliate criteria include the size of conflict, location of conflict, duration of the conflict, and other specific characteristic of the conflicting tasks. This study also defines the interference space percentage (ISP) and interference duration percentage (IDP) for further analyses and decision rules. Table 4 summarizes the categories and criteria for resolving space conflicts.

\section{Space conflict re-identification}

Once the original conflicts are resolved, the whole process of conflict identification and resolution must be executed again to ensure that there are no further space conflicts, which have occurred as a result of the adjusted space allocation or schedule 
Table 4. Categories of criteria for resolving space conflicts.

\begin{tabular}{|c|c|c|c|}
\hline \multirow[b]{2}{*}{ Category } & \multirow[b]{2}{*}{ Major criteria } & \multicolumn{2}{|l|}{ Affiliate criteria } \\
\hline & & Space-related & Time-related \\
\hline \multirow[t]{7}{*}{ Criteria } & Logic sequence & Size of conflict & Duration of conflict \\
\hline & Critical path & Size of conflict & Duration of conflict \\
\hline & Space divisibility & $\begin{array}{l}\text { Interference space } \\
\text { percentage (ISP) }\end{array}$ & $\begin{array}{l}\text { Interference duration } \\
\text { percentage (IDP) }\end{array}$ \\
\hline & Location change & Location of conflict & $\begin{array}{l}\text { Specific characteristic } \\
\text { of conflict tasks }\end{array}$ \\
\hline & Size modification & $\begin{array}{l}\text { Other related data } \\
\text { or characteristics }\end{array}$ & \\
\hline & $\begin{array}{l}\text { Start time of } \\
\text { occupancy }\end{array}$ & $\begin{array}{l}\text { Other related data } \\
\text { or characteristics }\end{array}$ & \\
\hline & $\begin{array}{l}\text { Length of occupancy } \\
\text { time }\end{array}$ & $\begin{array}{l}\text { Other related data } \\
\text { or characteristics }\end{array}$ & \\
\hline
\end{tabular}

rearrangement. Generally, this process can be completed in a short period. However, if further conflicts occur continuously or trigger subsequent problems, then the resolution strategy may require modification. In this circumstance, rearranging space usage or schedule may not solve all the conflicts effectively. Hence, the hybrid approach, such as applying alternative construction methods, may be more effective.

\section{Path demand analysis}

Although all the space conflicts have been resolved, the space planning is not yet complete. The final step is to ensure that there is enough path space for all the required laborers, equipment, and material transportation. Therefore, a minimum path width and height were defined as follows:

$$
\text { Minimum path width }=\operatorname{Max}\left\{\operatorname{All} \text { activities }\left[\begin{array}{c}
\operatorname{Min}(\text { width for labor }) \\
\operatorname{Min}(\text { width for equipment }) \\
\text { Min(width for labor/material) } \\
\text { Min(width for equipment/material) }
\end{array}\right]\right\}
$$

[4] Minimum path height $=\operatorname{Max}\{$ All activities

$\left.\left[\begin{array}{c}\text { Min(height for labor) } \\ \text { Min(height for equipment) } \\ \text { Min(height for labor/material) } \\ \text { Min(height for equipment/material) }\end{array}\right]\right\}$

The minimum path width and height can be derived from the above equations to examine if the path demands can be satisfied. Items that require examination include the following:

1. available path from the entrance to each working area;

2. available path from the entrance to each storage area;

3. available path from each working area to the associated storage area;

4. available path from each working area to the other working areas with the same activity;

5. available path from the current storage areas to the next stage storage areas.

When all path requirements are satisfied, the space planning is complete. Otherwise, appropriate adjustments must be made to eliminate insufficient path demands. However, if path demands remain unsatisfied, the aforementioned process of space conflict resolution must be re-executed for an alternative feasible solution.

\section{Case illustration}

A typical 12-story reinforced concrete residential building is used to demonstrate the identification and resolution of space conflicts via the decision criteria. This job site is approximately $1000 \mathrm{~m}^{2}$, with a total floor area of $5775 \mathrm{~m}^{2}$. The space planning for each floor requires various space requirements for survey, reinforcing steel, plumbing and electrical, scaffold, formwork, concrete, and management. Figure 6 displays the combined CAD drawings from the initial schedule as well as the space requirements of all subcontractors, which reveal many space conflicts.

To resolve the space conflicts, the decision support system initially compiles all these conflicts according to the space users, type of space, duration of the conflicts, location/size of the conflicts, and other related data of the competing activities. As mentioned previously, a list of conflicts is then 
Fig. 6. Conflicts identification for all subcontractors.

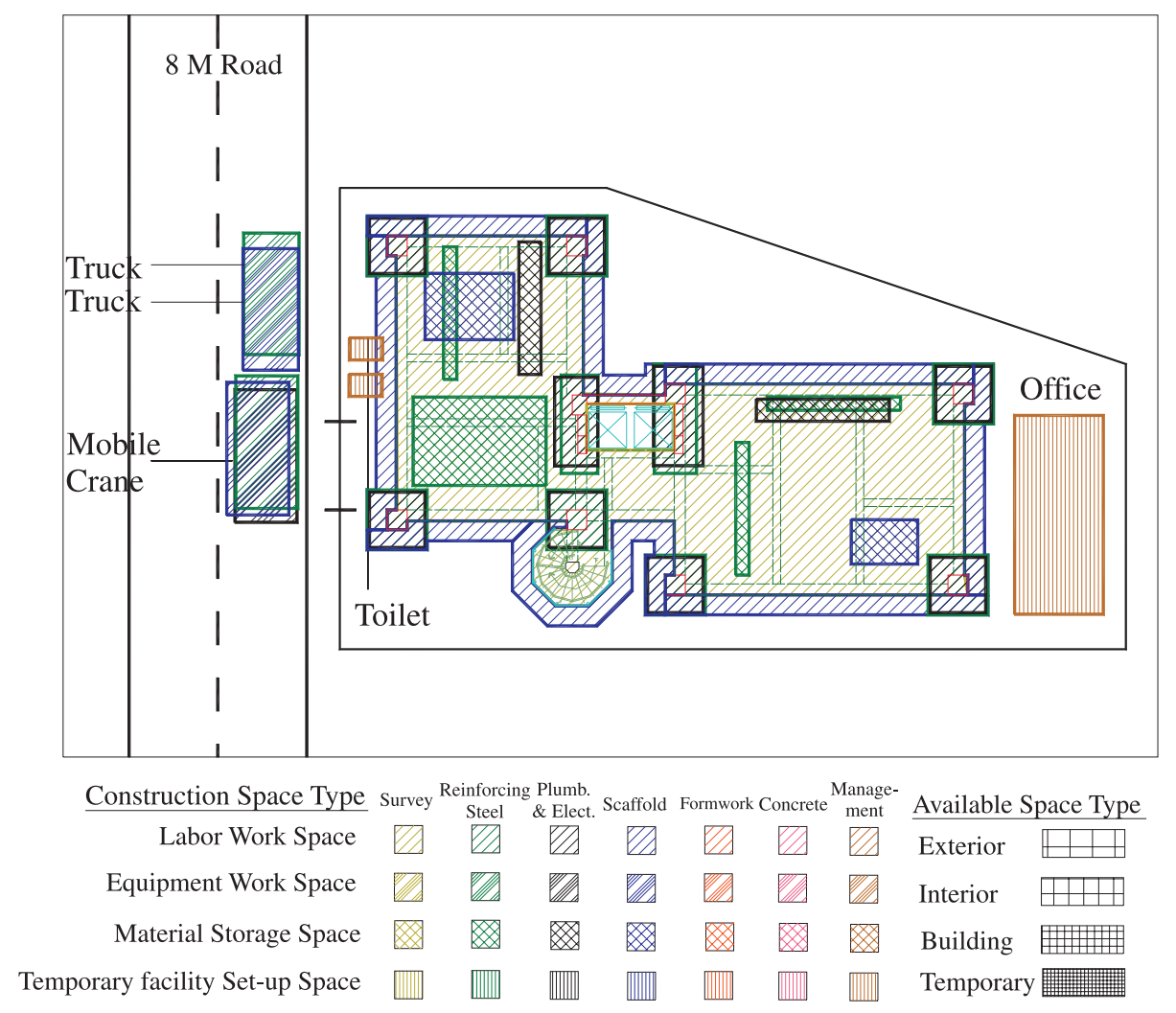

Table 5. Characteristics for conflict 7-1 (steel workers vs. plumbing workers).

\begin{tabular}{lll}
\hline & \multicolumn{2}{l}{ Working space } \\
\cline { 2 - 3 } Major criteria & Steel workers & Plumbing workers \\
\hline Logic sequence & Column bars erection $\rightarrow$ plumbing $\rightarrow$ ribs erection \\
Critical path & Yes & Yes \\
Space divisibility & No & No \\
Location change & No & No \\
Size modification & No & No \\
Start time of occupancy & 1 st day 8:00 a.m. & 1 st day 8:00 a.m. \\
Length of occupancy time & $4 \mathrm{~h}$ & $4 \mathrm{~h}$ \\
\hline
\end{tabular}

established (Table 3). Table 5 lists the characteristics for the space conflict 7-1 (steel workers vs. plumbing workers), via the developed criteria and procedures for conflicts analyses and resolution.

In this case, adjusting the size of the space requirement for subcontractors is unfeasible, since the floor area is very limited. A more suitable approach to resolve this problem is to adjust the planned schedule to avoid the conflicts. Figures 7 and 8 display that by splitting the reinforcing steel tasks of the columns to be erected, the conflicts between the reinforcing steel and plumbing/electrical can be eliminated. That is, steel workers must install the column bars first, then the plumbing/electrical workers have to follow the column bars for pipe installation. Finally, the steel workers must complete rib bar erection for the formwork workers to follow on. Since the start time of the plumbing/electrical workers is delayed for about 2 hours while waiting for the steel workers to install the column bars, the finish time of the plumbing/electrical work is thus delayed. Consequently, the rib bar completion is also delayed. Originally the formwork subcontractor was scheduled to begin at 2:00 p.m. However, because of the space conflicts and proposed resolution, the formwork workers must also delay their starting time.

After the space conflict between the steel workers and plumbing/electrical workers is resolved, the decision support system then examines if there are other subsequent unsolved conflicts. The two-dimensional drawing (Fig. 8) displays a dummy conflict between the scaffold and temporary toilet; no actual space conflict exists. That is, the toilet did not interfere with the scaffold on the 7 th floor because it was on the ground level. When all the other space conflicts are resolved and no further conflicts occur, the system will then verify if the path requirements are satisfied. Figure 9 illustrates the result of the path requirement verification of this case. The required minimum width for all the associated activities is $1 \mathrm{~m}$ and there are no path height constraints. Since 
Fig. 7. Conflict resolution between reinforcing steel and plumbing (8:00 a.m.).

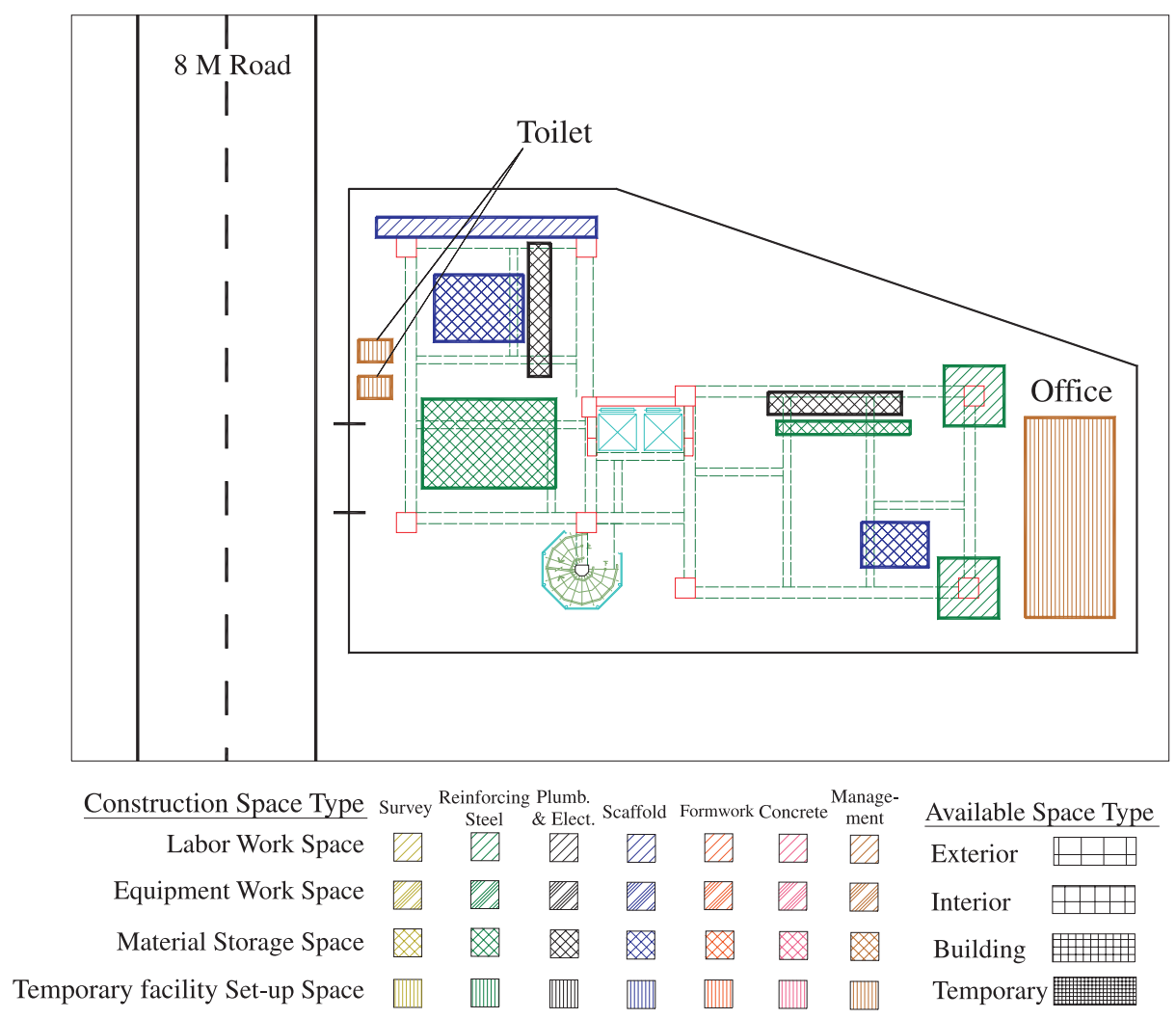

Fig. 8. Conflict resolution between reinforcing steel and plumbing (10:00 a.m.).

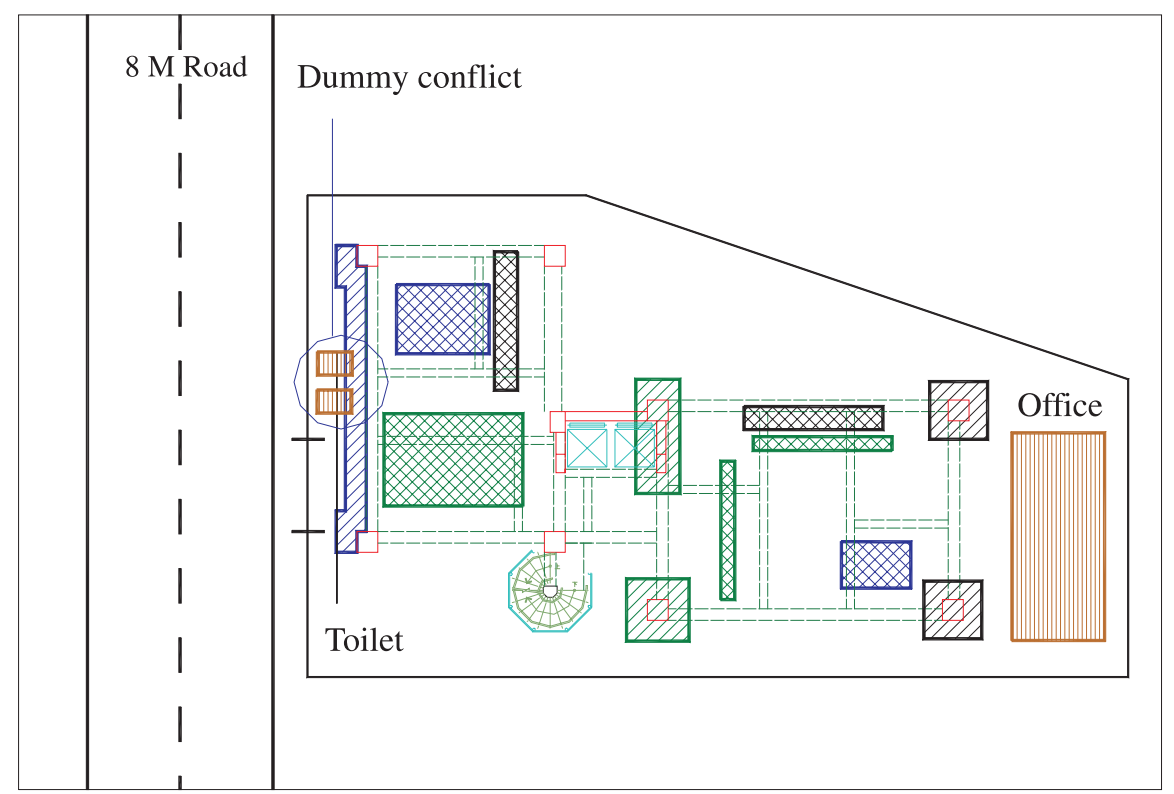

Construction Space Type Survey $\begin{gathered}\text { Reinforcing Plumb. } \\ \text { Steel }\end{gathered}$ Elect Scaffold Formwork Concrete ${ }_{\text {mant }}^{\text {Mana }}$

Labor Work Space

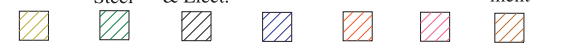

Available Space Type

Equipment Work Space

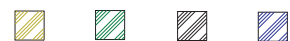

㧽

Material Storage Space

网

网网网 Building

Exterior $\square \square$

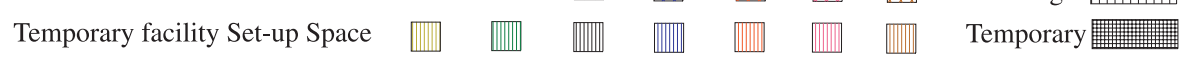


Fig. 9. Path requirements verification for various subcontractors.

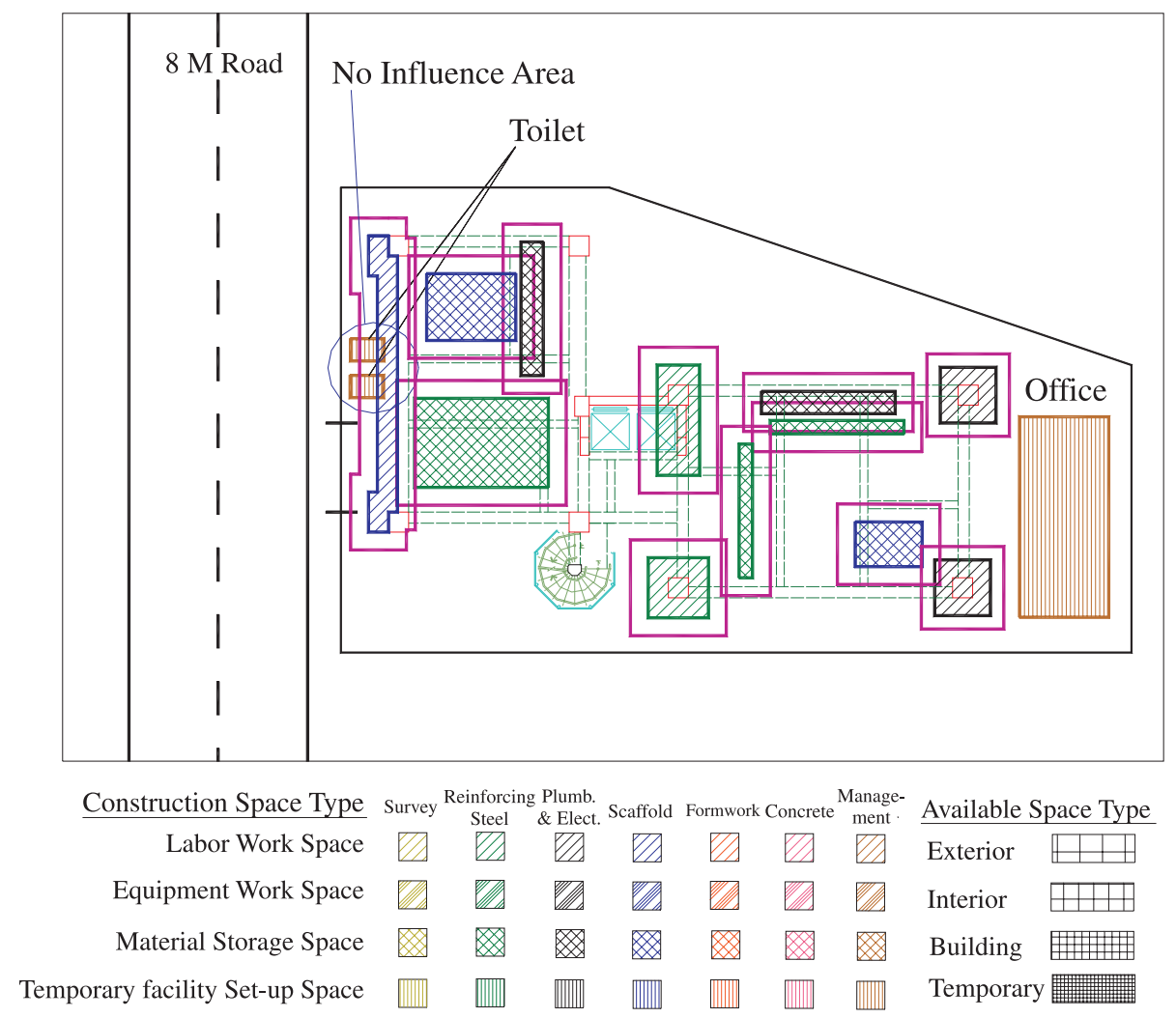

all the path requirements are also satisfied, the space planning process is complete. The decision support system will then forward these data to the schedule software and update the rearranged schedule.

\section{Discussion and conclusions}

Numerous workers, equipment, material, temporary facilities, and permanent structures share limited space during construction. Since space constraints may affect the moving path and productivity, it is essential to organize the available space efficiently such that the space conflicts are minimized. The space availability on a site may change due to time and scheduling arrangements. Thus, site layout and space planning has been a significant and complex problem for construction engineers. However, the construction industry has lacked efficient and systematic approaches for site layout and space planning. Therefore, when faced with a space conflict problem, many engineers rely on personal experience. However, this heuristic approach fails to consider that space availability may change with time and schedule, the possibility of alternative space, or the productivity loss due to path interference and space constraints.

This study established a procedure and criteria for identifying and resolving space conflicts. Previous researchers resolved this problem based on minimal travelling distance or cost between temporary facilities. However, this solution applies only to the transportation optimization process, and not directly to work optimization, nor the shortest working period. Alternatively, this study considered space availability due to time and schedule, productivity loss due to path inter- ference and space constraints, as well as the possibility of alternative space for conflict resolution and optimal usage. Herein, the CAD system was integrated with schedule software for dynamic identification of space conflicts on the job site for various subcontractors. Follow-up supplemental decision criteria were then provided for conflict analysis and resolution. Furthermore, a prototype decision support system which combined the criteria was developed to solve this significant and complex problem more efficiently and precisely. Finally, a case study demonstrated the use and development of this system, which will be very helpful to engineers and project management.

\section{Acknowledgement}

The author would like to thank the National Science Council of the Republic of China for financially supporting this research under Contract No. NSC89-2211-E-002-135.

\section{References}

Akinci, B., and Fischer, M. 1998. Time-space conflict analysis based on 4D production models. Proceedings of the ASCE Congress on Computing in Civil Engineering, Boston, Mass., pp. 342-353.

Akinci, B., Fischer, M., and Zabelle, T. 1998. A proactive approach for reducing non-value adding activities due to timespace conflicts. Proceedings of the 6th Annual Conference of the International Group for Lean Construction, Guaruja, Brazil, pp. $1-16$. 
Cheng, M.Y., and O'Connor, J.T. 1996. ArcSite: enhanced GIS for construction site layout. ASCE Journal of Construction Engineering and Management, 122(4): 329-336.

Hegazy, T., and Elbeltagi, E. 1999. EvoSite: evolution-based model for site lay-out planning. ASCE Journal of Computing in Civil Engineering, 13(3): 198-206.

Li, H., and Love, P.E.D. 1998. Site-level facilities layout using genetic algorithms. ASCE Journal of Computing in Civil Engineering, 12(4): 227-231.

Lin, K.L., and Haas, C.T. 1996. An interactive planning environment for critical operation. ASCE Journal of Construction Engineering and Management, 122(3): 212-222.

Riley, D.R. 1998. 4D space planning specification development for construction work spaces. Proceedings of the ASCE Congress on Computing in Civil Engineering, Boston, Mass., pp. 354-363.

Riley, D.R., and Sanvido, V.E. 1995. Patterns of construction-space use in multistory buildings. ASCE Journal of Construction Engineering and Management, 121(4): 464-473.

Riley, D.R., and Sanvido, V.E. 1997. Space planning method for multistory building construction. ASCE Journal of Construction Engineering and Management, 123(2): 464-473.

Thabet, W.Y., and Beliveau, Y.J. 1994. Modeling work space to schedule repetitive floors in multistory buildings. ASCE Journal of Construction Engineering and Management, 120(4): 96-116.

Thabet, W.Y., and Beliveau, Y.J. 1997. SCaRC: space-constrained resource-constrained scheduling system. ASCE Journal of Computing in Civil Engineering, 11(1): 48-59.
Tommelein, I.D., and Zouein, P.P. 1993. Interactive dynamic layout planning. ASCE Journal of Construction Engineering and Management, 119(2): 266-287.

Tommelein, I.D., Levitt, R.E., Hayes-Roth, B., and Confrey, T. 1991. Sight-Plan experiments: alternative strategies for site layout design. ASCE Journal of Computing in Civil Engineering, 5(1): 42-63.

Tommelein, I.D., Levitt, R.E., and Hayes-Roth, B. 1992a. Sitelayout modeling: how can artificial intelligence help? ASCE Journal of Construction Engineering and Management, 118(3): 594-611.

Tommelein, I.D., Levitt, R.E., and Hayes-Roth, B. 1992b. SightPlan model for site layout. ASCE Journal of Construction Engineering and Management, 118(4): 749-766.

Tserng, H.P., Veeramani, R., Kunigahalli, R., and Russel, J.S., 1996. A computer-integrated operation planning system for autonomous land fill compaction. Journal of Automation in Construction, 5: 39-50.

Varghese, K., and O'Connor, J.T. 1995. Routing large vehicles on industrial construction site. ASCE Journal of Construction Engineering and Management, 121(1): 1-10.

Yeh, I-C. 1995. Construction-site layout using annealed neural network. ASCE Journal of Computing in Civil Engineering, 9(3): 201-207.

Zouein, P.P., and Tommelein, I.D. 1999. Dynamic layout planning using a hybrid incremental solution method. ASCE Journal of Construction Engineering and Management, 125(6): 400-408. 
Copyright $\odot 2003$ EBSCO Publishing 